BMJ Paediatrics Open

\title{
Impact of lockdown and school closure on children's health and well-being during the first wave of COVID-19: a narrative review
}

\author{
Luis Rajmil (1) , ${ }^{1}$ Anders Hjern, ${ }^{2}$ Perran Boran, ${ }^{3}$ Geir Gunnlaugsson, ${ }^{4}$ \\ Olaf Kraus de Camargo, ${ }^{5}$ Shanti Raman (1) ,, 7 and on behalf of International \\ Society for Social Pediatrics \& Child Health (ISSOP) and International Network for \\ Research on Inequalities in Child Health (INRICH) COVID-19 Working Group
}

To cite: Rajmil L, Hjern A, Boran $\mathrm{P}$, et al. Impact of lockdown and school closure on children's health and well-being during the first wave of COVID-19: a narrative review. BMJ Paediatrics Open 2021;5:e001043. doi:10.1136/ bmjpo-2021-001043

- Additional supplemental material is published online only. To view, please visit the journal online (http://dx.doi.org/ 10.1136/bmjpo-2021-001043).

Received 2 February 2021 Accepted 1 May 2021
Check for updates

(c) Author(s) (or their employer(s)) 2021. Re-use permitted under CC BY-NC. No commercial re-use. See rights and permissions. Published by BMJ.

For numbered affiliations see end of article.

Correspondence to Dr Luis Rajmil; 12455Irr@ comb.cat

\section{ABSTRACT}

Background In the context of containment measures against the COVID-19 pandemic, the aims were to examine the impact of lockdown and school closures on childs' and adolescents' health and well-being and social inequalities in health.

Methods Literature review by searching five databases until November 2020. We included quantitative peer-reviewed studies reporting health and well-being outcomes in children (0-18 years) related to closure measures' impact due to COVID-19. A pair of authors assessed the risk of bias of included studies. A descriptive and narrative synthesis was carried out.

Findings Twenty-two studies, including high-income middle-income and low-income countries, fulfilled our search criteria and were judged not to have an increased risk of bias. Studies from Australia, Spain and China showed an increase in depressive symptoms and decrease in life satisfaction. A decrease in physical activity and increase in unhealthy food consumption were shown in studies from two countries. There was a decrease in the number of visits to the emergency department in four countries, an increase in child mortality in Cameroon and a decrease by over $50 \%$ of immunisations administered in Pakistan. A significant drop of $39 \%$ in child protection medical examination referrals during 2020 compared with the previous years was found in the UK a decrease in allegations of child abuse and neglect by almost one-third due to school closures in Florida, and an increase in the number of children with physical child abuse trauma was found in one centre in the USA

Interpretation From available reports, pandemic school closure and lockdown have adverse effects on child health and well-being in the short and probably long term. We urge governments to take the negative public health consequences into account before adopting restrictive measures in childhood.

\section{INTRODUCTION}

The global COVID-19 pandemic caused by SARS-CoV-2 is the largest since the Spanish flu pandemic in 1918, with almost 100 million confirmed cases and over two million deaths. ${ }^{1}$ This virus impacts relatively few children in terms of severe morbidity or mortality;

\section{What is already known}

School closure and lockdown were measures initialIy adopted almost worldwide in the first wave to fight the COVID-19 pandemic.

- Lockdown and school closure cause disproportionate impacts on the most vulnerable populations.

- Decisions on how to apply quarantine and school closures should be based on the best available evidence.

\section{What this study adds}

- The negative impact of school closures and lockdown has been felt by children across diverse geographies, involving high and low-income settings.

- Containment measures have produced a range of adverse effects including an increase in depressive symptoms, decrease in satisfaction with life, decrease in immunisation and an increase in unhealthy lifestyle.

- Along with a decrease in emergency presentations, there was also a significant decrease in the number of child abuse and neglect allegations and child protection medical assessments.

however, they experience heightened adversity as governments intervene with drastic social control measures. ${ }^{2}$ Over 1.5 billion children were out of school during the first peak, and economic insecurity has affected the most vulnerable, with several potential adverse effects. ${ }^{3}$

Governments around the world have reacted in variable ways with strategies to mitigate the pandemic. A review on the effect of school closure in the transmission of the SARS-CoV-2 in the general population predicted that school closures alone would prevent only $2 \%-4 \%$ of deaths, much less than other social 

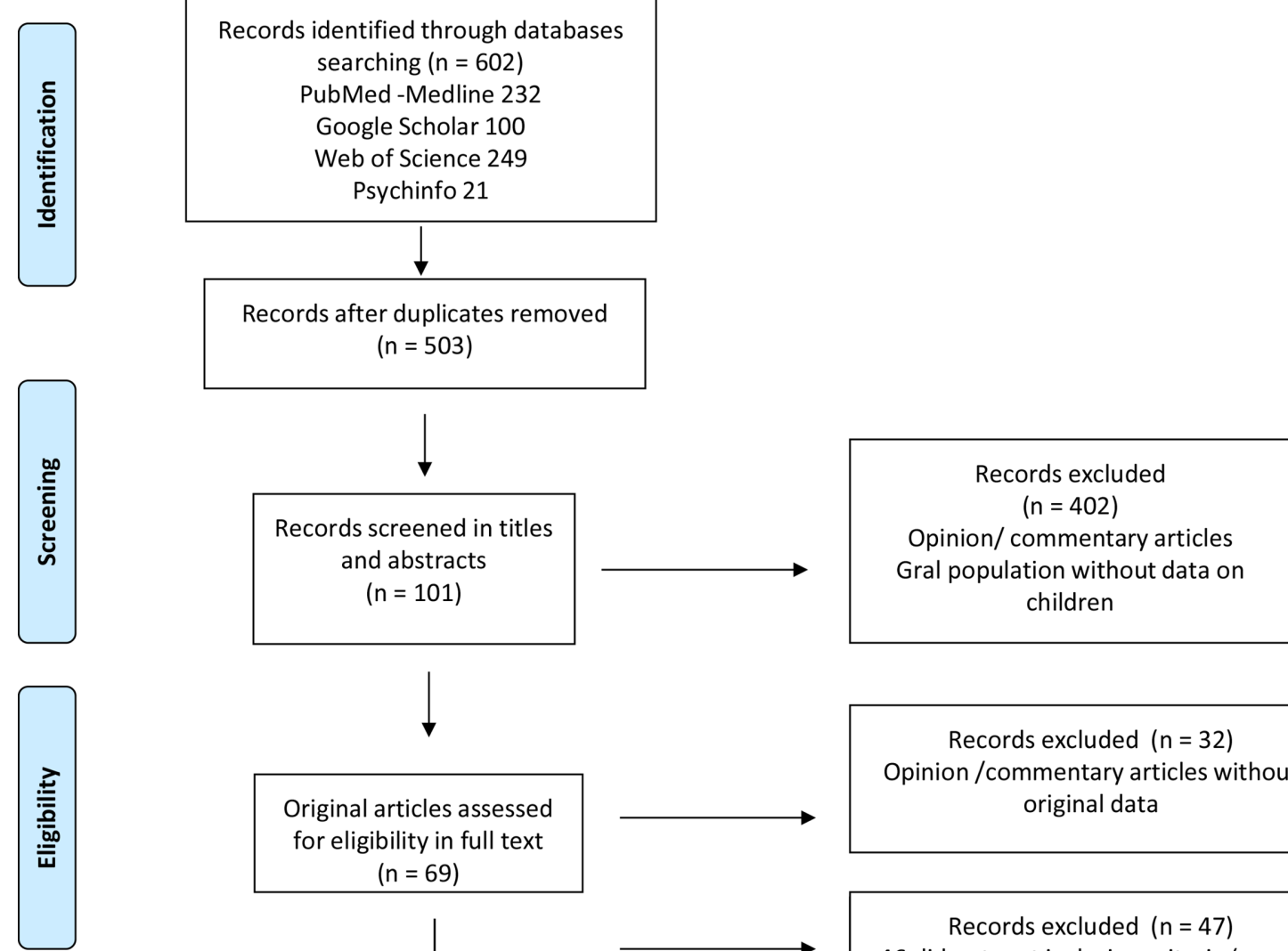

Original articles assessed for eligibility in full text $(n=69)$
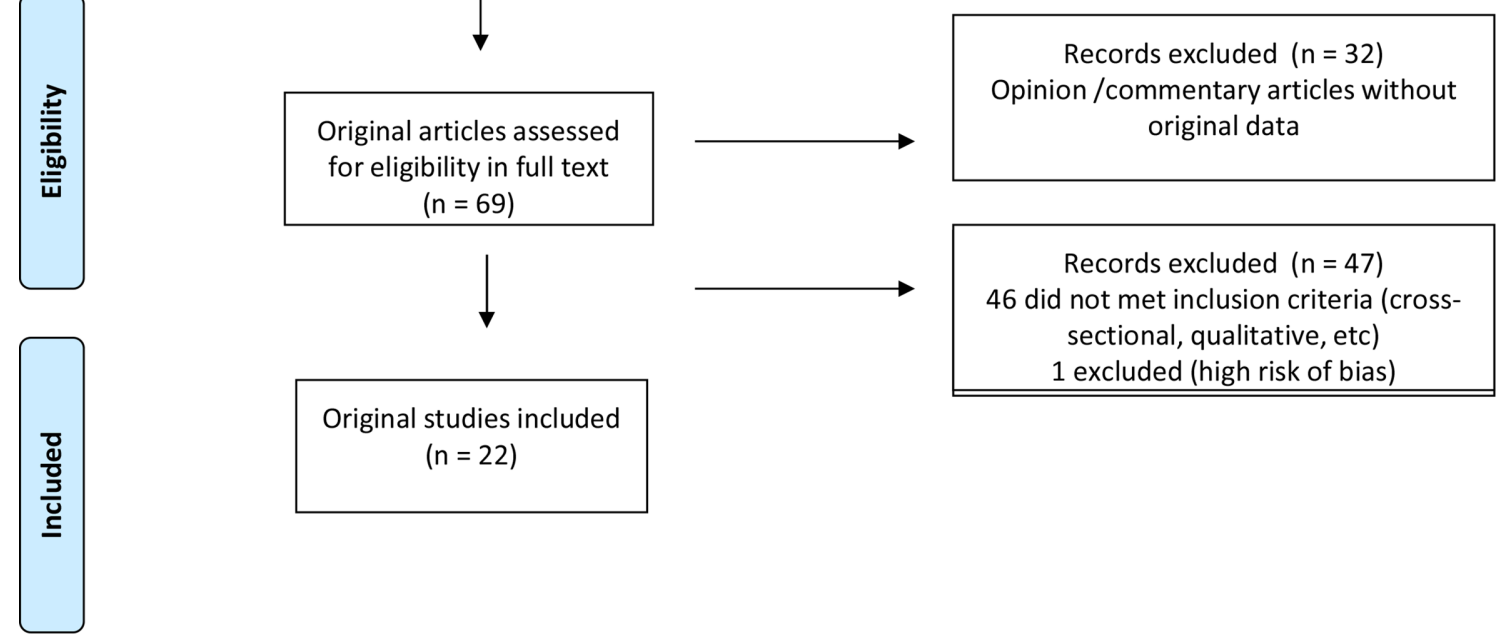

Original studies included $(n=22)$

Figure 1 Sample.

distancing interventions. ${ }^{4}$ On the other hand, school closures carry high social and economic costs for people across communities associated with interrupted learning, poor nutrition, gaps in childcare, the unintended strain on healthcare systems, rise in dropout rates from school and social isolation, among other effects. ${ }^{5}$

The pandemic is a universal crisis that has affected all population groups across the globe. For some children, the impact could be lifelong, particularly the most vulnerable groups and those with less economic, educational and social resources. ${ }^{6}$ In response to school closures and depending on settings, online teaching accentuated the digital divides between those who have access and those without access. ${ }^{7}$ Moreover, schools have health promotion potential by implementing diverse health interventions and opportunities to advocate for reforms and innovations to promote all students' health. ${ }^{8}$ Arguments over whether to close schools or not to prevent transmission during a pandemic need to weigh in the potential health promotional benefits for children by attending school, in particular, those in vulnerable situations. This disconnect needs to be addressed with closer cooperation that would revitalise not only their educational potential but also child and adolescent health and wellbeing $^{9} 10$

Large-scale 'lockdowns' as occurred with little warning in many countries, involving the complete shutting down of all economic activity, along with stringent travel bans, with punitive action for any violation, have been shown to cause

\section{Box 1 Definitions of lockdown and school closure}

Although the term lockdown is not well defined, it is used to nominate any measure adopted to contain the pandemic employing social distancing measures.

- Lockdown measures range considerably, from mandatory total confinement in the home during prolonged periods to be only a recommendation to reduce social interactions and avoid nonessential work as much as possible.

- School closure and online classes or home schooling was the measure adopted in almost all cases during the first wave of the COVID-19 for primary and secondary schools in all included studies. 


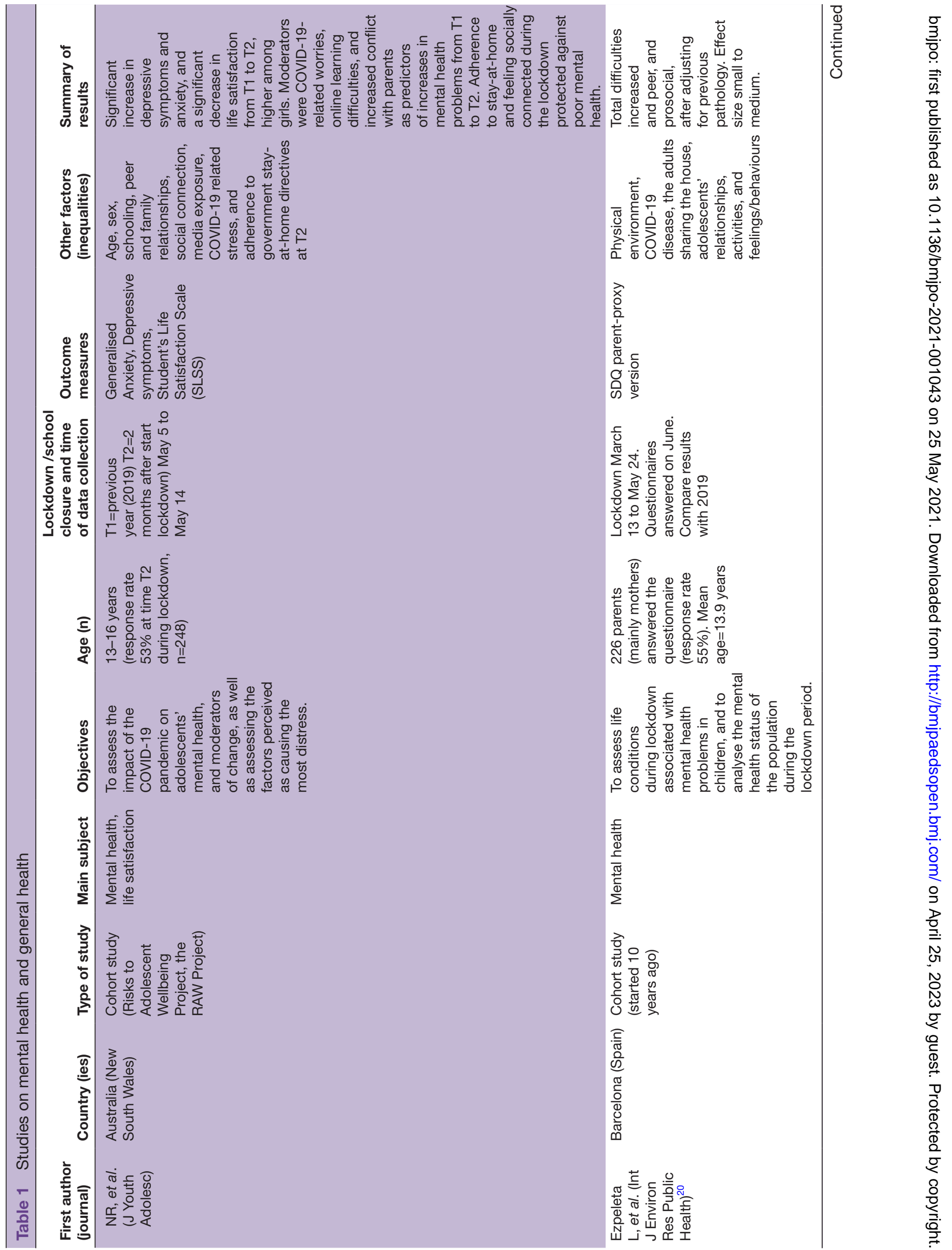




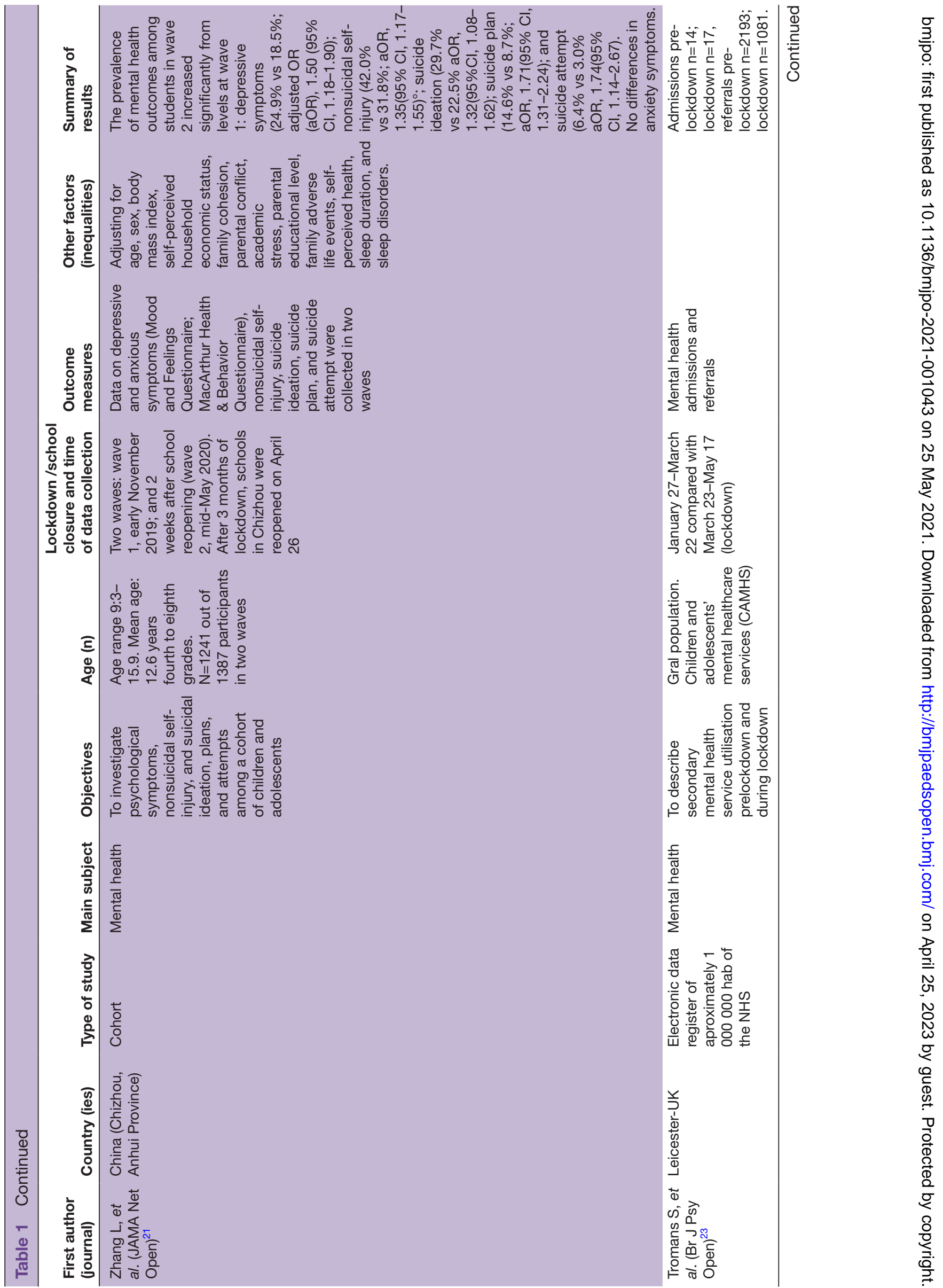




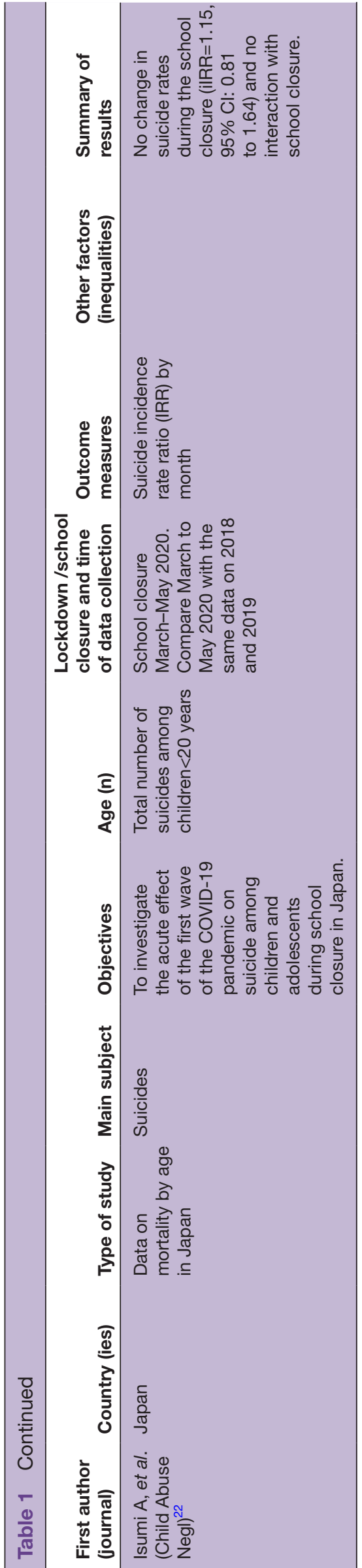

disproportionate impact on the most vulnerable populations, for example, in India. ${ }^{11}$ Decisions on how to apply quarantine and school closure should be based on the best available evidence. In situations where quarantine is deemed necessary, officials should quarantine individuals no longer than required, provide clear rationale for quarantine and information about protocols, and ensure sufficient supplies are provided. ${ }^{12}$ In summary, during the fight against coronavirus in several countries, while adopting social distancing measures in order to reduce the spread of a disease that mainly causes direct harm to adults, children's needs have not been taken into due consideration. ${ }^{13}$ For children, the risks of such measures might be greater and have a potential for short-term and long-term negative effect, mostly in low-income and middle-income countries and also in highincome countries, especially in the prenatal and in early childhood periods. ${ }^{14}$

At the current stage of the pandemic, it is important to summarise and compile existing information on the pandemic's impact on child health given the measures that have been taken. The aim of this narrative review is, therefore, to study the impact of COVID-19 lockdown measures and school closures on child's and adolescent's health and well-being. Our research questions were (a) What impact do lockdowns and closure of schools have on child health and well-being? and (b) to what extent do the effects of confinement increase social inequalities in child health?

\section{METHODS}

A literature review was carried out by search in PubMed, Medline, Psychinfo, Web of Science and Google Scholar, using the following terms: '(Lockdown OR School closure) AND (COVID-19 OR SARS-CoV-2) AND (children OR adolescent) AND (secondary effects OR physical OR mental)'. Secondary hand search also was done. The time period analysed was 1 December 2019 until 24 November 2020.

The research questions followed the Population Intervention Comparison Outcome tool ${ }^{15}$ : $\mathrm{p}=0-18$ years, $\mathrm{I}=$ school closures and/or lockdown due to COVID-19; $\mathrm{C}=\mathrm{a}$ comparison group-could be compared with same population before or unexposed population as control, $\mathrm{O}=$ physical, developmental or mental health, psychosocial (would include child maltreatment, domestic violence, violence etc), access and use of healthcare services.

The Preferred Reporting Items of Systematic reviews MetaAnalyses (http://www.prisma-statement.org/) guideline was followed, although some items were not applicable given the characteristics of included studies.

The risk of bias of each included study was assessed by a pair of authors (PB, AH, LR) using the Mixed Methods Appraisal Tool $^{16}$ and was further stratified as low, intermediate or high risk by consensus of each pair of authors. In the first step, the risk of bias of each study was independently assessed, and in the second step, a consensus was achieved according to the number and characteristics of negative scores. 


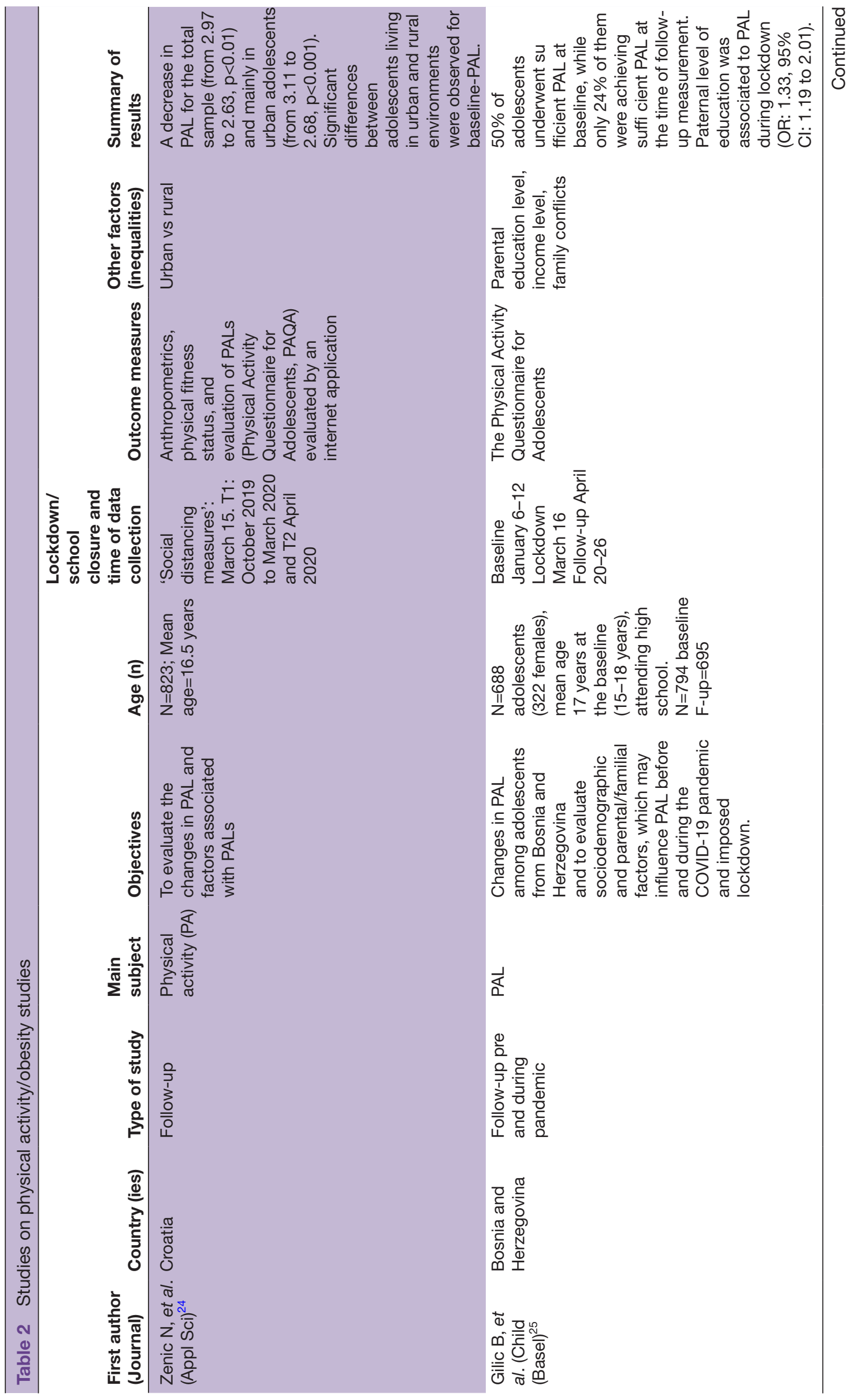




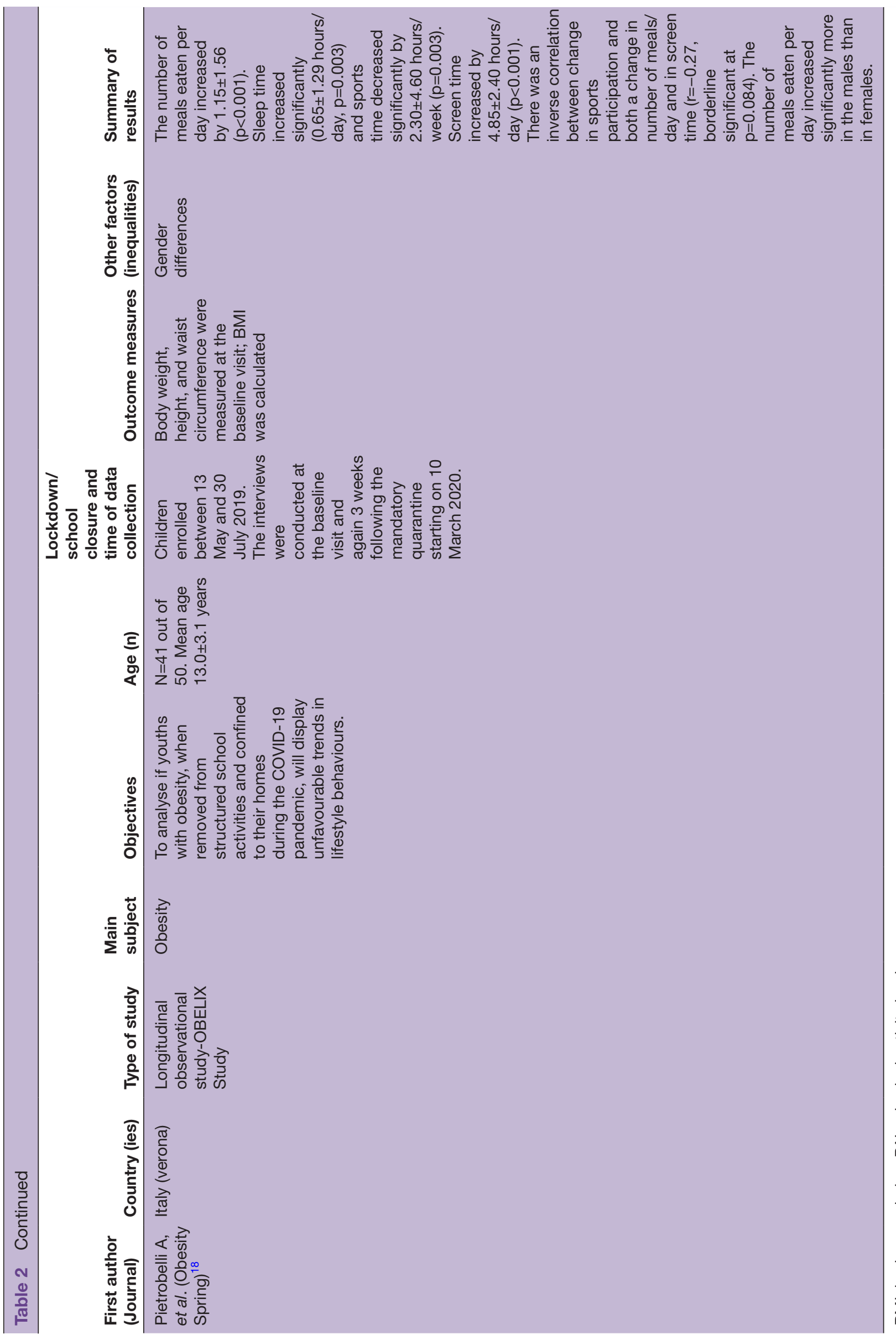


Inclusion criteria: all quantitative studies from peer-review literature describing studies that provided primary data about child (0-18 years) health and well-being related to the measures of school closure and any level of lockdown adopted regarding of COVID-19 and the impact on child health were included. Articles in Catalan, Danish, English, French, German, Icelandic, Italian, Norwegian, Spanish, Portuguese, Swedish and Turkish were included in the first screening. Following the initial screening, all included articles in the study were published in English-language journals. Original studies (cohort studies, repeated cross-sectional studies etc) were included if they reported children's data. We also included studies on changes in access/use of healthcare services during lockdown.

Exclusion criteria: studies that did not present separate data on childhood population, as well as commentaries, theoretical frameworks, without the analysis of empirical data, and preprint not peer-reviewed articles were excluded. Comments not based on specific empirical data (eg, opinion papers, protocols, letters without specific reviewed data) were also left out. Furthermore, articles regarding clinical manifestations and school transmission of COVID-19 impact on adults (ie, teachers, parents, except if it included specifically secondary impact on children) and cross-sectional studies analysing retrospective data without comparison or control group were also excluded.

Procedures: abstracts obtained by the initial search strategy were assessed for possible inclusion by at least two authors. Full-text papers of the studies were obtained in doubtful cases and independently evaluated by the authors. Differences of opinion on inclusion were decided by discussion and consensus among all authors (ie, one study that was initially included in the first screening was excluded by agreement of the authors due to a high risk of bias associated to the type of study and data collection; see the online supplemental material).

Data extraction: LR led data extraction that was checked initially by $\mathrm{AH}$ and $\mathrm{PB}$, followed by a consensus with the rest of the authors. Data extraction included a summary of findings to answer the research questions and characteristics of the included studies: author; setting (country: international, national or regional study); type of study; age(s); lockdown (time in days/months); school closure and lockdown (time period); type of outcome; impact on child health and social inequalities.

Analysis: a meta-analysis was not possible to carry out given the nature of the study design and heterogeneity of the findings. Consequently, the authors carried out a descriptive and narrative synthesis of the results. First, studies were grouped according to their main subject and methodological similarities. LR, AH and PB identified the thematic content and described the results, followed by discussion among all the authors. The results were then analysed and summarised to distil out findings to subsequently integrate those with the rest of studies.

\section{RESULTS}

Study selection and risk of bias.

After excluding one study due to a high risk of bias, ${ }^{17} 22$ studies were included in the synthesis (figure 1). Included studies were from 15 countries, thereof 11 European. Eleven studies were a follow-up of children, while the rest of the studies analysed clinical databases, mortality registers or registries on child abuse and maltreatment.

Almost all of the included studies showed low to moderate risk of bias, except one study that was considered as moderate-high risk of bias; the sample was small, an unstructured questionnaire was administered, anthropometric measurements were taken at baseline only, and measures used were not appropriate for age (online supplemental Table 1). ${ }^{18}$

Exposure measure (box 1)

School closure was the most commonly adopted restrictive measure, although in most countries closure of schools and home confinement were both implemented at the same time; in some cases, the latter was established as a mandatory norm and especially for the child population, and in other cases, it was given as a general recommendation. The impact of school closure and lockdown or any measure of restriction such as stay-at-home, mandatory or recommended, was assessed between 2 weeks and 2-3 months after implementing these measures.

Outcome measures

Five studies addressed mental health, ${ }^{19-23}$ three studies analysed physical activity and obesity, ${ }^{18} 2425$ three studies examined diabetes mellitus, ${ }^{26-28}$ eight studies approached changes in the access and use of healthcare services, ${ }^{29-36}$ while three studies analysed data regarding child abuse and violence. ${ }^{37-39}$

\section{Mental health}

One Australian study showed a significant increase in depressive symptoms and anxiety and a significant decrease in life satisfaction during school closure and lockdown, mainly in girls (table 1) ${ }^{19}$ A Spanish study gave evidence to a worse total difficulty score of the Strengths and Difficulties Questionnaire according to parent-proxy responses. ${ }^{20} \mathrm{~A}$ cohort of Chinese children and adolescents showed that all indicators of depressive symptoms (nonsuicidal self-injury, suicide ideation, a suicide plan and suicide attempt) deteriorated significantly during lockdown compared with previous baseline data. ${ }^{21}$ No difference in the number of suicides was found in a Japanese study. ${ }^{22}$ Referrals to the mental healthcare services for children and adolescents decreased during the lockdown in England compared with the previous year. ${ }^{23}$

\section{Physical activity, obesity}

A decrease in physical activity level (PAL) was found in a child cohort from Croatia (from 2.97 to $2.63, \mathrm{p}<0.01$ ) and significant differences were observed between adolescents living in urban and rural environments (table 2). ${ }^{24}$ A study from Bosnia \& Herzegovina found that $50 \%$ of 


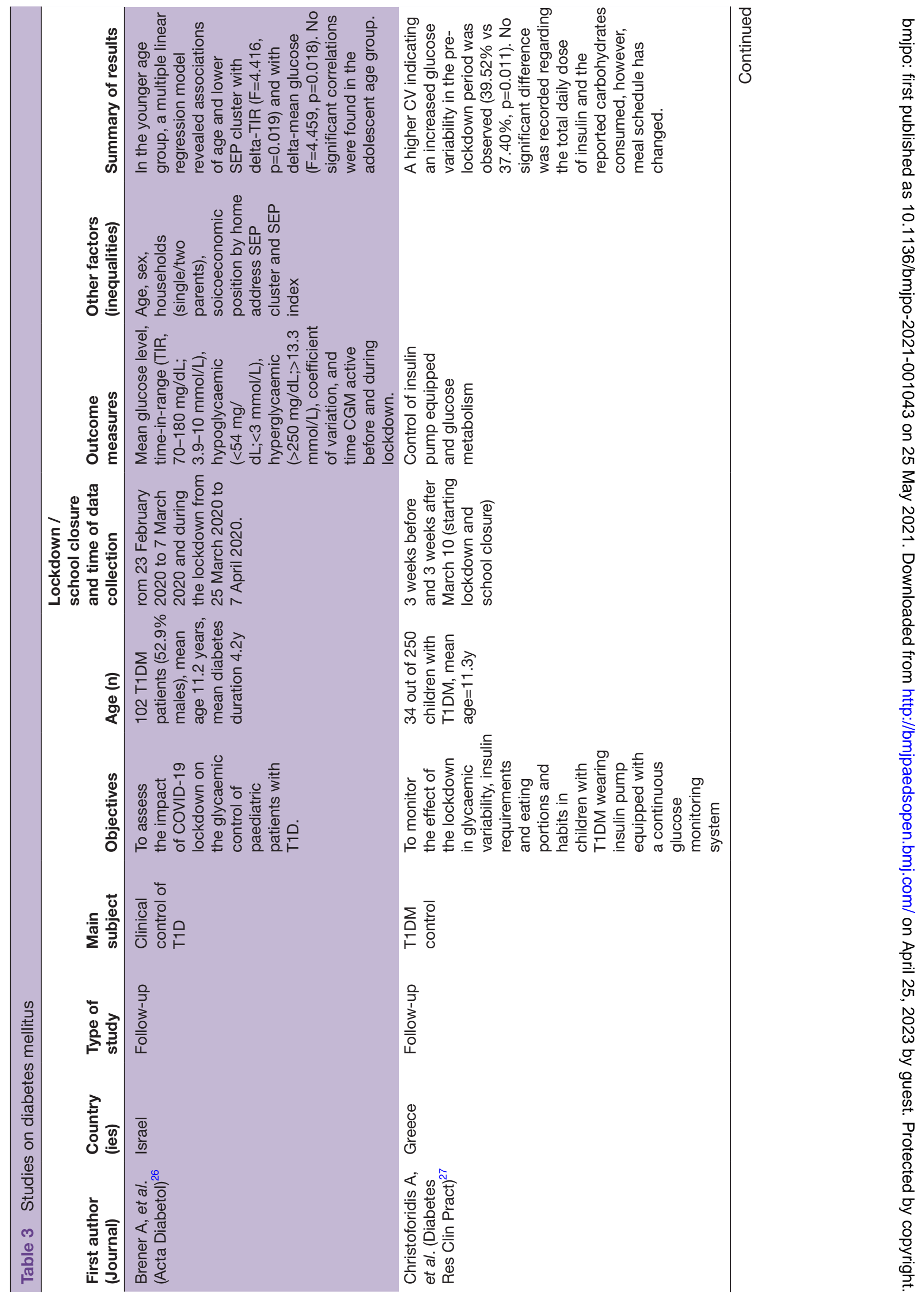




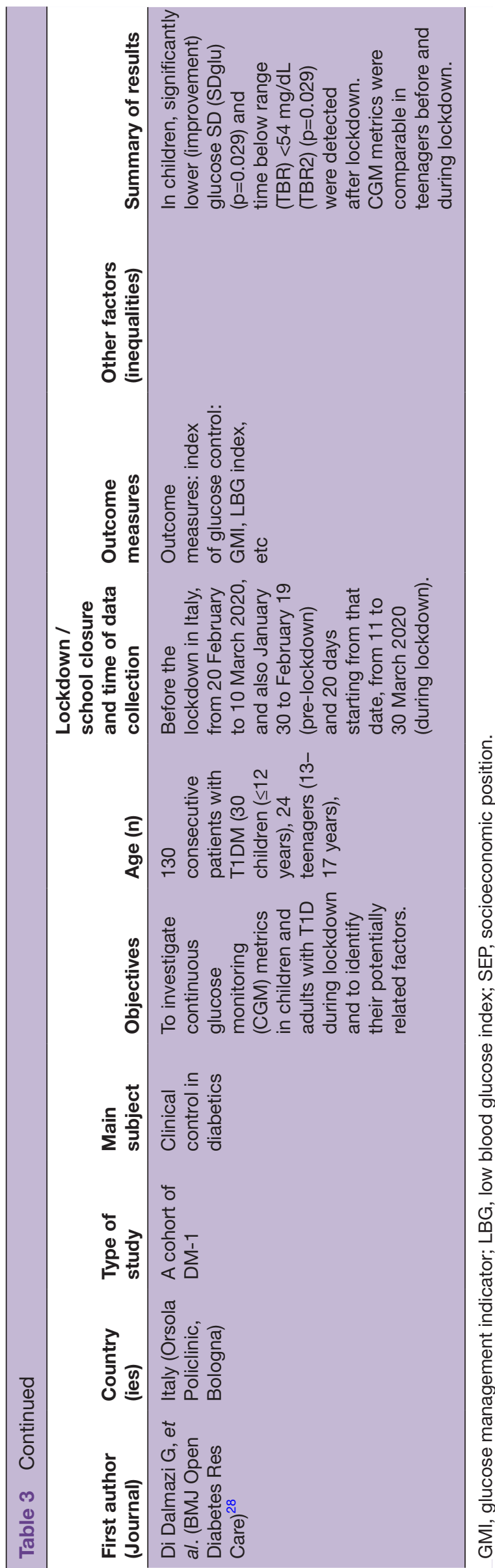

adolescents achieved sufficient PAL at baseline, while $24 \%$ at the time of follow-up measurement during lockdown; moreover, paternal education level was associated with PAL during lockdown (OR: 1.33, 95\% CI 1.19 to 2.01).$^{25}$ The follow-up of Italian obese adolescents found that the number of meals per day increased by $1.15 \pm 1.56$ $(p<0.001)$ during the lockdown and also unhealthy food consumption and sedentary behaviours. ${ }^{18}$

\section{Diabetes mellitus}

Three studies on children with type 1 diabetes mellitus from Israel, ${ }^{26}$ Greece $^{27}$ and Italy ${ }^{28}$ showed no changes or improvements in glucose control indicators. However, in some cases, younger age and low family socioeconomic status were associated with worse control during the lockdown period (table 3 ).

\section{Healthcare services access/use}

There were no differences in the proportion of caesarean deliveries between the observation and control groups in a Chinese study. Furthermore, birth weight in the observation group during lockdown was higher than in the control group among infants born $>34$ gestational weeks (table 4). ${ }^{29}$

In Canada, the number of visits to the emergency department (ED) due to injuries in children decreased in 2 months in 2020 compared with the same period from 1993 to $2019 .{ }^{30}$ An increase in the number of admissions due to seizures was found in an Italian children's hospital. ${ }^{32}$ In another Italian study, the mean paediatric ED daily consultations decreased from 326.3 (95\% CI 299.9 to 352.7) in March-May 2019 to 101.4 (95\% CI 77.9 to 124.9 ) in the same period in $2020(\mathrm{p}<0.001){ }^{34}$

Similarly, a decrease in the number of visits by $63.8 \%$ to the ED was observed compared with the same period in 2019 in a German hospital except for malignant/neoplastic diseases. ${ }^{33}$ An Australian study found a $47.2 \%$ decrease in total visits to the ED (26 871 vs $14170)$, with a significant difference in daily mean. Conversely, there was a $35 \%$ (485 vs 656 ) increase in mental health diagnoses, while neonatal visits did not change significantly. ${ }^{31}$

There was a $52.5 \%$ decline in the daily average of the total number of vaccinations administered during lockdown than baseline data in Pakistan. ${ }^{35}$ A study from Cameroon showed a drastic drop in hospitalisations, and child mortality rates doubled comparing with the previous year. $^{36}$

\section{Violence, abuse against children}

Routinely collected clinical data on Child Protection Medical Examinations (CPME) from Birmingham (UK) showed a significant drop of $39 \%$ (95\% CI $14 \%$ to $57 \%$ ) in CPME referrals during 2020 compared with previous years, mainly associated with decreased school staff referrals. ${ }^{37}$ A study from the US found an increase in the 


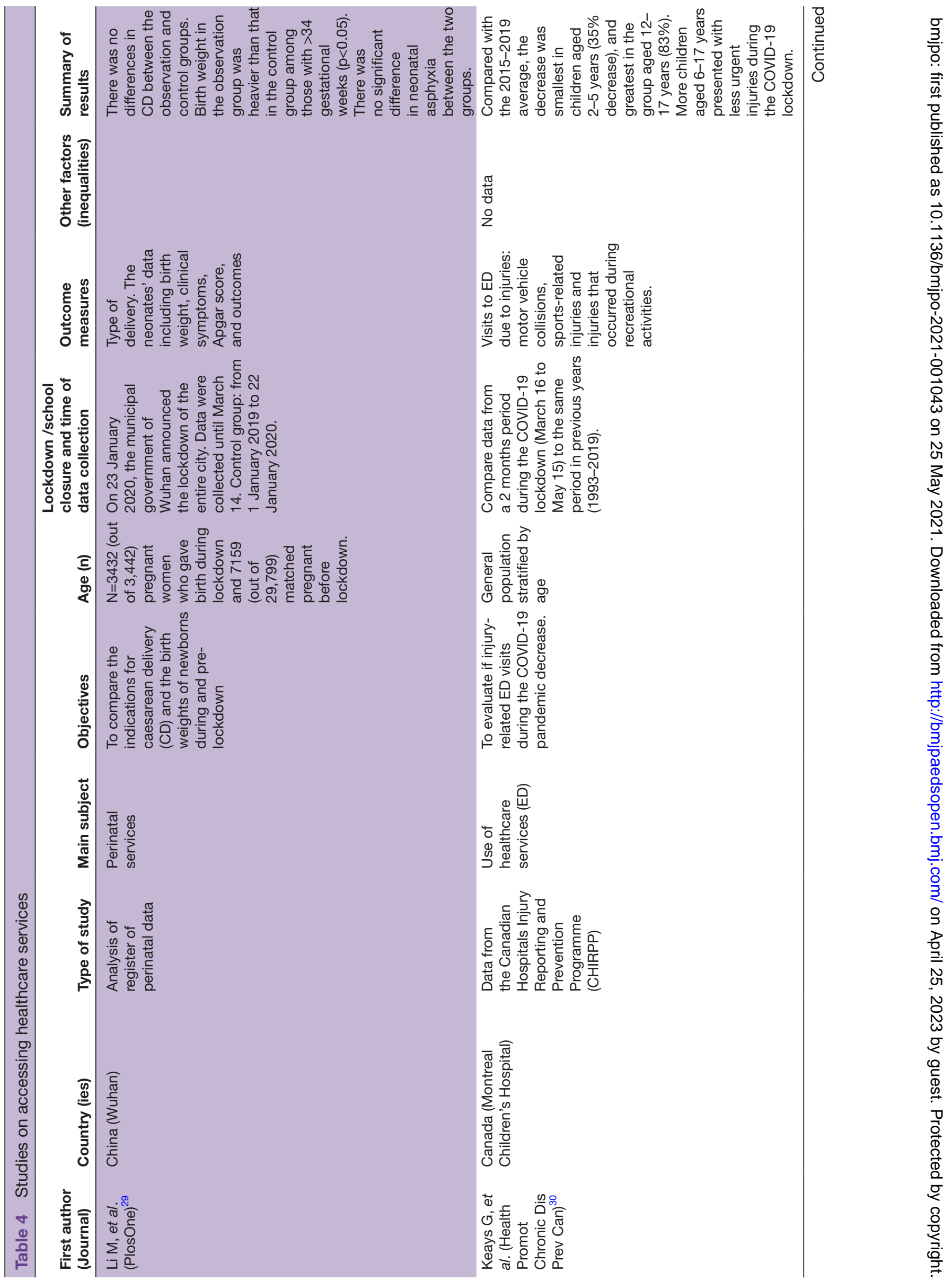




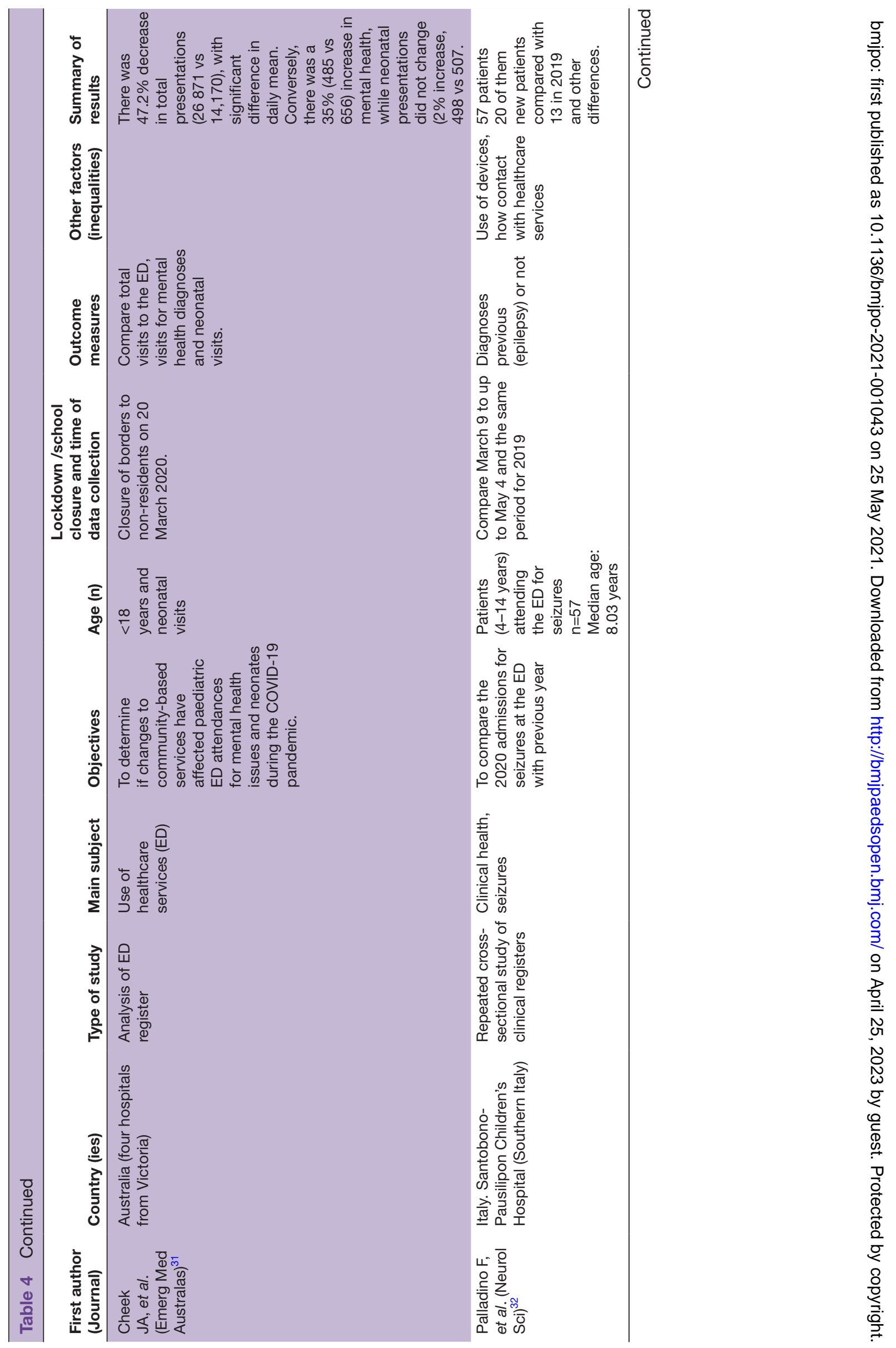




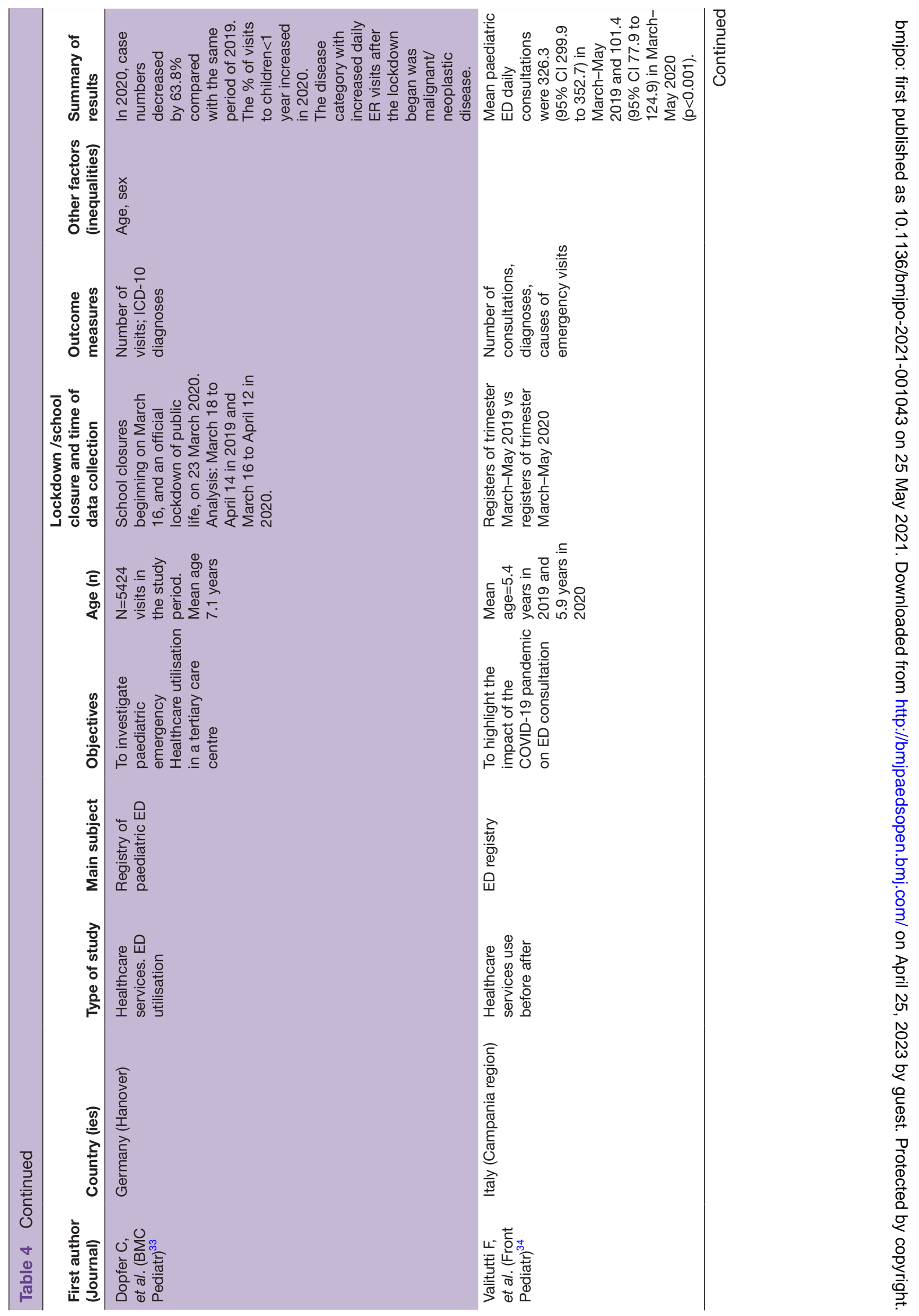




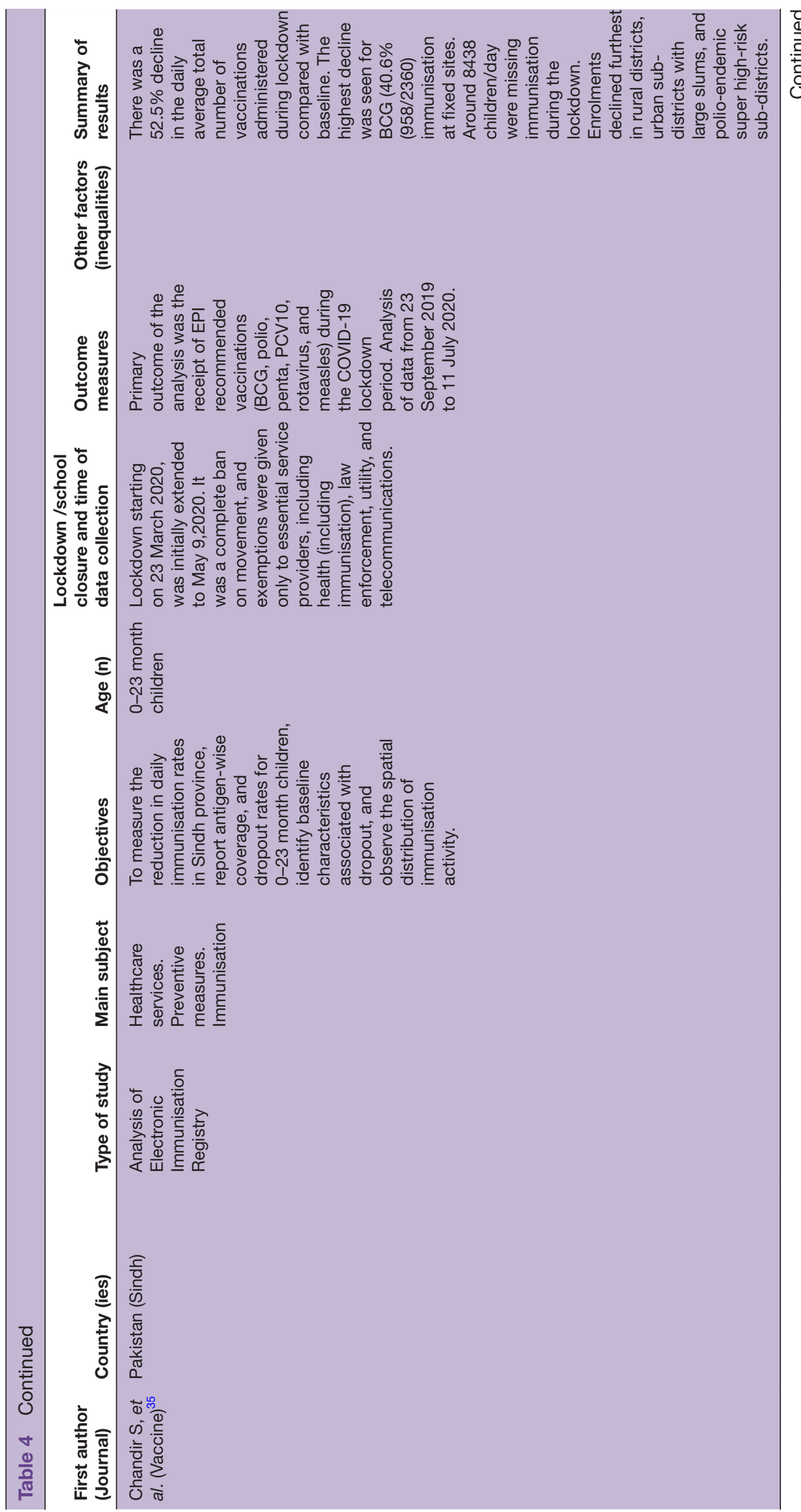


number of children with physical child abuse trauma, ${ }^{38}$ and the Florida child abuse allegation data showed a decrease in $27 \%(n=15000)$ in the number of allegations of child abuse and neglect comparing with the same 2 months of 2019 (table 5). ${ }^{39}$

\section{DISCUSSION}

This narrative review provides summaries of peerreviewed published evidence on the impact of school closures and lockdown on child health, well-being and access to healthcare, during the first wave of COVID-19. The results show worse mental health status of children and adolescents from disparate geography and socioeconomic background, reduced physical activity and increased sedentary behaviours. There were changes in the access and use of healthcare services as manifested by decrease in the ED visits, increased child mortality in a study from Cameroon and a reduction on immunisation coverage in Pakistan. Finally, an increased risk of child abuse and violence against children due to decreased access to general and specific care services during the period of lockdown and school closure was seen in the USA and UK. The effect of these measures of restriction indicates an increase in social inequalities. However, only a few of the studies focus specifically on analysing the impact on social determinants of child health. We found a significant negative effect in the most vulnerable groups (ie, higher mortality and less vaccination coverage in the studies from low-income and middle-income countries) and more significant negative impact on mental and physical health and child abuse and maltreatment in the most vulnerable child population in studies from highincome countries.

The results of this 'nonnatural experiment' are generalisable to most of the countries that applied any level of lockdown or confinement and closure of schools, although each country has different healthcare and education systems and social and redistribution policies. Confinement has produced an increase in previously existing inequalities with respect to access to basic living conditions and care services, with more difficulties in households with fewer resources. ${ }^{40}$

The results of the present study add to previous analyses on the impact of quarantine and school closure during previous epidemic outbreaks worldwide. ${ }^{12}$ The latter analysed the impact and reported negative psychological effects including post-traumatic stress symptoms, confusion and anger. On the other hand, social isolation exacerbates personal and collective vulnerabilities while limiting accessible and familiar support options. ${ }^{41}$ Many countries have seen an increase in demand for domestic violence services and reports of increased risk for children not attending schools, a pattern similar to previous episodes of social isolation associated with epidemics and pandemics. ${ }^{42}$

The results show an impact on mental health and physical activity mainly in the adolescent population. However, likely, these factors have also affected younger 


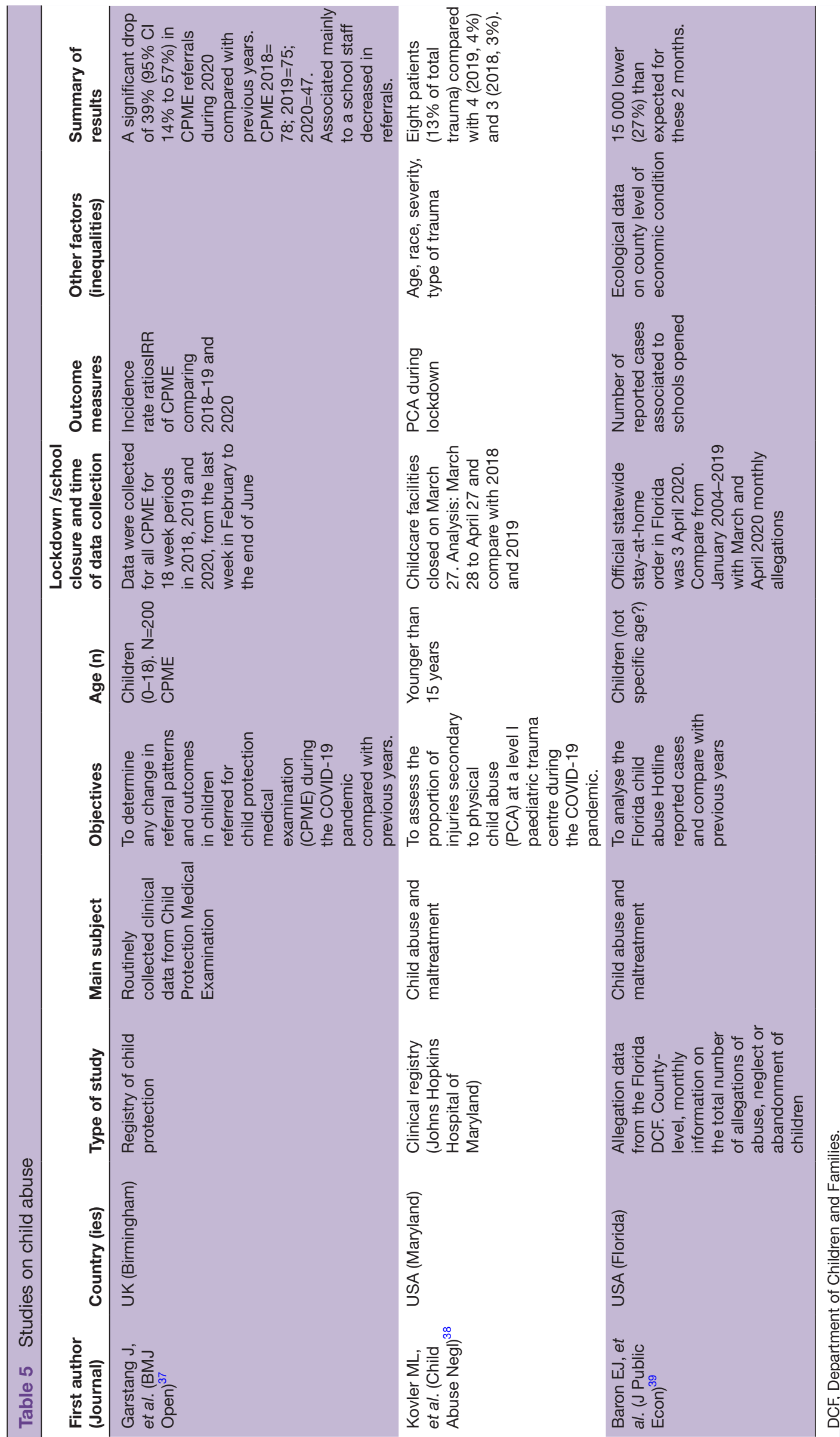


children, a fact that needs to be assessed in future studies. Another review on the impact of COVID-19 on families and children found an increase in parental stress related to the suspension of classroom activities, social isolation measures, nutritional risks, children's exposure to toxic stress, depressive and anxiety symptoms, especially in previously unstructured homes, and a lack of physical activities. ${ }^{43}$ Some cross-sectional reports found important differences between households of different socioeconomic status regarding home learning and with important potential implications for the long-term impact that the unprecedented circumstances. ${ }^{44}$ Moreover, some studies carried out modelisations on the impact of inequalities and lost school learning. Christakis et $a t^{45}$ compared the full distribution of estimated years of life lost (YLL) due to COVID-19 under both 'schools open' and 'schools closed' conditions and observed a $98.1 \%$ probability that school opening would have been associated with a lower total YLL than school closure. On the other hand, Azevedo $e t a t^{46}$ found that between 0.3 and 0.9 years of schooling losses adjusted for quality, bringing down the effective years of basic schooling that students achieve during their lifetime from 7.9 years to between 7.0 and 7.6 years. This would be associated with lost earnings in the amount between US $\$ 6472$ and US $\$ 25680$ dollars over a typical student's lifetime, exacerbating inequalities.

\section{Strengths and limitations}

One of the strengths of this narrative review is the inclusion of peer-reviewed, longitudinal data or repeated cross-sectional data based on comparable measures. This makes the association between exposure to lockdown and school closure and outcome measures analysed more robust. Nonetheless, there are limitations. First, few of the studies analysed data from low-income and middleincome countries or social inequalities as independent factors, which should be addressed in future studies. Second, the exposure measures that we analysed, both school closure and lockdown, varied between countries and also the period from the beginning of the measures, and the time outcomes were assessed. This fact makes it difficult to evaluate the impact according to the level and duration of confinement and also to establish a clear association between exposure and outcomes. However, all the included studies present at least the timeline for initiating the measures adopted and evaluating the results. Third, educational, healthcare and redistributive policies before the pandemic conditioned each country's responses and results, and these factors must also be taken into account in future studies. Finally, the measures analysed here may have long-term effects and, therefore, future studies will need to factor in longer follow-up.

\section{CONCLUSIONS}

This narrative review attempted to provide the best available evidence on the impact of pandemic-related restrictive measures on child's and adolescent's health. The findings call for the attention of decision-makers to take into account the risks and benefits for children's health, with respect to public health measures that are adopted. Policymakers and researchers should look into other much less disruptive social distancing interventions given that lockdown measures greatly affect children and with more negative effects than benefits in the short and probably also in the long term. As other public health experts are urging, ${ }^{47}$ we suggest that a comprehensive public health approach is needed in response to this pandemic with particular attention given to children. Social determinants and medical requirements should be addressed simultaneously, with equity and human rights as overarching principles.

\section{Author affiliations}

${ }^{1}$ Pediatric and Public Health Specialist, Retired, Barcelona, Spain

${ }^{2}$ Centre for Health Equity Studies, Stockholm University/Karolinska Institutet, Stockholm, Sweden

${ }^{3}$ Department of Pediatrics, Marmara University School of Medicine, Istanbul, Turkey ${ }^{4}$ Faculty of Social and Human Sciences, University of Iceland, Reykjavík, Iceland

${ }^{5}$ Department of Pediatrics, McMaster University, Hamilton, Ontario, Canada

${ }^{6}$ Department of Community Paediatrics, South Western Sydney Local Health District, Liverpool, New South Wales, Australia

${ }^{7}$ Women's \& Children's Health, University of New South Wales, Sydney, New South Wales, Australia

\section{Twitter Luis Rajmil @LuisRajmil}

Contributors LR, PB and AH conceptualised the paper, reviewed full-text articles, extracted the data and wrote the first draft of the manuscript. GG, SR and OK contributed to searches and screening of papers and helped to revise the paper and consider implications. All authors contributed to revision of the final version of the manuscript.

Funding The authors have not declared a specific grant for this research from any funding agency in the public, commercial or not-for-profit sectors.

Competing interests None declared.

Patient consent for publication Not required.

Provenance and peer review Not commissioned; externally peer reviewed.

Data availability statement All data relevant to the study are included in the article or uploaded as supplementary information.

Supplemental material This content has been supplied by the author(s). It has not been vetted by BMJ Publishing Group Limited (BMJ) and may not have been peer-reviewed. Any opinions or recommendations discussed are solely those of the author(s) and are not endorsed by BMJ. BMJ disclaims all liability and responsibility arising from any reliance placed on the content. Where the content includes any translated material, BMJ does not warrant the accuracy and reliability of the translations (including but not limited to local regulations, clinical guidelines, terminology, drug names and drug dosages), and is not responsible for any error and/or omissions arising from translation and adaptation or otherwise.

Open access This is an open access article distributed in accordance with the Creative Commons Attribution Non Commercial (CC BY-NC 4.0) license, which permits others to distribute, remix, adapt, build upon this work non-commercially, and license their derivative works on different terms, provided the original work is properly cited, appropriate credit is given, any changes made indicated, and the use is non-commercial. See: http://creativecommons.org/licenses/by-nc/4.0/.

ORCID iDs

Luis Rajmil http://orcid.org/0000-0002-6625-0649

Shanti Raman http://orcid.org/0000-0002-4546-3231

\section{REFERENCES}

1 Johns Hopkins University \& Medicine. Coronavirus resource center, 2021. Available: https://coronavirus.jhu.edu/ [Accessed 20 Jan 2021]. 
2 Raman S, Harries M, Nathawad R, et al. Where do we go from here? a child rights-based response to COVID-19. BMJ Paediatr Open 2020;4:e000714

3 Gupta S, Jawanda MK. The impacts of COVID-19 on children. Acta Paediatr 2020;109:2181-3.

4 Viner RM, Russell SJ, Croker H, et al. School closure and management practices during coronavirus outbreaks including COVID-19: a rapid systematic review. Lancet Child Adolesc Health 2020;4:397-404

5 UNESCO. Adverse consequences of school closure. adverse consequences of school closures, 2020. Available: https://en. unesco.org/covid19/educationresponse/co

6 United Nations. Policy brief: the impact of COVID-19 on children, 2020. Available: https://unsdg.un.org/sites/default/files/2020-04/ 160420 Covid Children Policy Brief.pdf

7 Gunnlaugsson G, Whitehead TA, Baboudóttir Fatou N'dure, et al. Use of digital technology among adolescents attending schools in Bissau, Guinea-Bissau. Int J Environ Res Public Health 2020;17:8937-21.

8 Lee A, Lo A, Li Q, et al. Health promoting schools: an update. Appl Health Econ Health Policy 2020;18:605-23.

9 The Lancet. COVID-19: the intersection of education and health. Lancet 2021;397:253.

10 Jourdan D, Gray NJ, Barry MM. Viewpoint supporting every school to become a foundation for healthy lives. Lancet child Adolesc Health 2021;4642:1-9.

11 Dore B. Covid-19: collateral damage of lockdown in India. BMJ 2020;369:m1711-2

12 Brooks SK, Webster RK, Smith LE, et al. The psychological impact of quarantine and how to reduce it: rapid review of the evidence. Lancet 2020;395:912-20.

13 Crawley E, Loades M, Feder G, et al. Wider collateral damage to children in the UK because of the social distancing measures designed to reduce the impact of COVID-19 in adults. BMJ Paediatr Open 2020;4:e000701.

14 Yoshikawa $\mathrm{H}$, Wuermli AJ, Britto PR. Effects of the globa coronavirus Disease-2019 pandemic on early childhood development: short- and long-term risks and mitigating program and policy actions. J Pediatr 2020;2507:1-9.

15 Canberra $U$ of. Evidence-based practice in health. PICO framework, 2021. Available: https://canberra.libguides.com/c.php?g=599346\& $\mathrm{p}=4149722 \#: \sim$ :text=Practitioners of Evidence-Based Practice, and facilitate the literature search.\&text=PICO [Accessed 20 Jan 2021]

16 Hong QN, Pluye P, bregues S F. Methods, mixed appraisal tool (MMAT), 2018. Can Intellect Prop Off Ind Canada. Available: http:// hdl.handle.net/10609/93312 [Accessed 20 Jan 2021].

17 Chahal R, Kirshenbaum JS, Miller JG, et al. Higher executive control network coherence buffers against Puberty-Related increases in internalizing symptoms during the COVID-19 pandemic. Biol Psychiatry Cogn Neurosci Neuroimaging 2021;6:79-88.

18 Pietrobelli A, Pecoraro L, Ferruzzi A, et al. Effects of COVID-19 Lockdown on lifestyle behaviors in children with obesity living in Verona, Italy: a longitudinal study. Obesity 2020;28:1382-5.

19 Magson NR, Freeman JYA, Rapee RM. Risk and protective factors for prospective changes in adolescent mental health during the COVID-19 pandemic. J Youth Adolesc 2020.

20 Ezpeleta L, Navarro JB, de la Osa N, et al. Life conditions during COVID-19 lockdown and mental health in Spanish adolescents. Int J Environ Res Public Health 2020;17:7327-13.

21 Zhang L, Zhang D, Fang J, et al. Assessment of mental health of Chinese primary school students before and after school closing and opening during the COVID-19 pandemic. JAMA Netw Open 2020;3:e2021482.

22 Isumi A, Doi S, Yamaoka Y, et al. Do suicide rates in children and adolescents change during school closure in Japan? the acute effect of the first wave of COVID-19 pandemic on child and adolescent mental health. Child Abuse Negl 2020;110:104680.

23 Tromans S, Chester V, Harrison $\mathrm{H}$, et al. Patterns of use of secondary mental health services before and during COVID-19 lockdown: observational study. BJPsych Open 2020;6:1-6.

24 Zenic N, Taiar R, Gilic B. Levels and changes of physical activity in adolescents during the COVID-19 pandemic: Contextualizing urban vs. Rural Living Environment. Appl Sci 2020;10.

25 Gilic B, Ostojic L, Corluka M, et al. Contextualizing Parental/Familial influence on physical activity in adolescents before and during COVID-19 pandemic: a prospective analysis. Children 2020;7:125.

26 Brener A, Mazor-Aronovitch K, Rachmiel M, et al. Lessons learned from the continuous glucose monitoring metrics in pediatric patients with type 1 diabetes under COVID-19 lockdown. Acta Diabetol 2020;57:1511-7.

27 Christoforidis A, Kavoura E, Nemtsa A, et al. Coronavirus lockdown effect on type 1 diabetes management on children wearing insulin pump equipped with continuous glucose monitoring system. Diabetes Res Clin Pract 2020;166:108307.

28 Di Dalmazi G, Maltoni G, Bongiorno C, et al. Comparison of the effects of lockdown due to COVID-19 on glucose patterns among children, adolescents, and adults with type 1 diabetes: CGM study. BMJ Open Diabetes Res Care 2020;8:e001664-9.

29 Li M, Yin H, Jin Z, et al. Impact of Wuhan lockdown on the indications of cesarean delivery and newborn weights during the epidemic period of COVID-19. PLoS One 2020;15:e0237420.

30 Keays G, Freeman D, Gagnon I. Injuries in the time of COVID-19. Health Promot Chronic Dis Prev Can 2020;40:336-41.

31 Cheek JA, Craig SS, West A, et al. Emergency department utilisation by vulnerable paediatric populations during the COVID-19 pandemic. Emerg Med Australas 2020;32:870-1.

32 Palladino F, Merolla E, Solimeno M, et al. Is Covid-19 lockdown related to an increase of accesses for seizures in the emergency department? an observational analysis of a paediatric cohort in the southern Italy. Neurol Sci 2020;41:3475-83.

33 Dopfer C, Wetzke M, Zychlinsky Scharff A, et al. COVID-19 related reduction in pediatric emergency healthcare utilization - a concerning trend. BMC Pediatr 2020;20:427.

34 Valitutti F, Zenzeri L, Mauro A, et al. Effect of population Lockdown on pediatric emergency room demands in the era of COVID-19. Front Pediatr 2020;8:521.

35 Chandir S, Siddiqi DA, Mehmood M, et al. Impact of COVID-19 pandemic response on uptake of routine immunizations in Sindh, Pakistan: an analysis of provincial electronic immunization registry data. Vaccine 2020;38:7146-55

36 Chelo D, Mekone Nkwelle I, Nguefack F, et al. Decrease in hospitalizations and increase in deaths during the Covid-19 epidemic in a pediatric Hospital, Yaounde-Cameroon and prediction for the coming months. Fetal Pediatr Pathol 2021;40:18-31.

37 Garstang J, Debelle G, Anand I, et al. Effect of COVID-19 lockdown on child protection medical assessments: a retrospective observational study in Birmingham, UK. BMJ Open 2020;10:e042867.

38 Kovler ML, Ziegfeld S, Ryan LM. Increased proportion of physical child abuse injuries at a level I pediatric trauma center during the Covid-19 pandemic. Child Abuse Negl 2020;104756.

39 Baron EJ, Goldstein EG, Wallace CT. Suffering in silence: how COVID-19 school closures inhibit the reporting of child maltreatment. J Public Econ 2020;190:104258.

40 Statistics O, Directorate D. COVID-19 : Protecting people and societies, 2020. Available: https://www.oecd.org/inclusive-growth/ resources/COVID-19-Protecting-people-and-societies.pdf [Accessed 2 Mar 2021].

41 Usher K, Bhullar N, Durkin J, et al. Family violence and COVID-19: increased vulnerability and reduced options for support. Int J Ment Health Nurs 2020;29:549-52.

42 Ghosh R, Dubey MJ, Chatterjee S, et al. Impact of COVID -19 on children: special focus on the psychosocial aspect. Minerva Pediatr 2020;72:226-35.

43 Araújo LAde, Veloso CF, Souza MdeC, et al. The potential impact of the COVID-19 pandemic on child growth and development: a systematic review. J Pediatr 2020. doi:10.1016/j.jped.2020.08.008. [Epub ahead of print: 23 Sep 2020].

44 Andrew A, Cattan S, Dias MC. Inequalities in Children's Experiences of Home Learning during the COVID-19 Lockdown in England, 2020. Available: https://www.ifs.org.uk/uploads/publications/wps/ WP202026-Inequalities-childrens-experiences-home-learningduring-COVID-19-lockdown-England.pdf

45 Christakis DA, Van Cleve W, Zimmerman FJ. Estimation of US children's educational attainment and years of life lost associated with primary school closures during the coronavirus disease 2019 pandemic. JAMA Netw Open 2020;3:e2028786.

46 Azevedo JP, Hasan A, Goldemberg D. Simulating the potential impacts of COVID-19 school closures on schooling and learning outcomes: a set of global estimates. world bank GR, 2020. Available: http://www.worldbank.org/prwp.\%0Ahttp://pubdocs. worldbank.org/en/798061592482682799/covid-and-educationJune17-r6.pdf

47 Prasad V, Sri BS, Gaitonde R. Bridging a false dichotomy in the COVID-19 response: a public health approach to the 'lockdown' debate. BMJ Glob Health 2020;5:e002909-5. 